the infant in whom selective withdrawal of intensive care is a realistic and honest option.

\author{
Department of Paediatrics \\ and Child Health, \\ University of Leeds, \\ Clarendon Wing, \\ The General Infirmary at Leeds, \\ Leeds LS2 9NS \\ 1 Graham M, Levene MI, Trounce JQ, Rutter N. Prediction of cerebral palsy \\ in very low birthweight infants: prospective ultrasound study. Lancet 1987 \\ ii: $593-6$. \\ 2 Stewart AL, Reynolds EOR, Hope PL, et al. Probability of neurodevelop- \\ mental disorders estimated from ultrasound appearance of brains of very \\ mental disorders estimated from ultrasound appearance
preterm infants. Dev Med Child Neurol 1987;29:3-11. \\ 3 Cooke RWI. Early and late cranial ultrasonographic appearances and outcome \\ in very low birthweight infants. Arch Dis Child 1987;62:931-7. \\ 4 Tudehope DI, Masel J, Mohay H, et al. Neonatal cranial ultrasonography as \\ predictor of 2 year outcome of very low birthweight infants. Aust Paediat \\ f 1989;25:66-71. \\ 5 Trounce JQ, Rutter N, Levene MI. Periventricular leucomalacia and intra- \\ ventricular haemorrhage in the preterm neonate. Arch Dis Child 1986;61: \\ 1196-202.
}

M I LEVENE

\section{Incidence and prevalence}

The terms incidence and prevalence are occasionally used as though they are synonymous, this, however, is to misuse them because, not only do they have quite distinct meanings but there is an arithmetical relationship between them.

The point prevalence of a given condition is the number of cases in a specific population at a point in time. The incidence is the number of new cases appearing in the population over a specified period of time. An analogy may be drawn with water flowing into and draining out of a basin. The quantity of water in the basin is equivalent to the prevalence and the water flowing in is the incidence. Obviously the level of water in the basin (the prevalence) will vary according to the rate at which water is flowing in (the incidence) and the rate it is flowing out (which can be expressed by the duration of the disease). Thus: prevalence $\propto$ incidence $\times$ duration. If two conditions are met, namely that: (a) the incidence rate is constant (for most disease conditions this is a reasonable assumption but in an epidemic situation-for example, the cyclical variation found with many communicable diseases-this condition will not be met) and (b) the mean duration of the disease is constant, then prevalence $=$ incidence $\times$ duration $(P=I \times D)$.

The relevance of this relationship to paediatric practice may be considered at both general and specific levels. At the general level I regularly ask medical undergraduates for examples of outstanding successes in the medical therapeutic armamentarium and how have these successes affected the prevalence of disease. It is salutary that some have no ready answer while disconcertingly few mention antibiotics or insulin. Almost invaribly they state that successful therapeutic measures reduce the prevalence of disease. While this may be true for some conditions-for example, tuberculosis where both incidence and duration of active disease have been dramatically curtailed after the introduction of antituberculous drugs-most of today's diseases have increased in prevalence as a result of successful treatment. Conditions that were previously incompatible with survival beyond childhood are now found in adults and even in second childhood. Juvenile diabetes, cystic fibrosis, end stage renal failure, severe mental and/or physical impairment all come to mind as examples. Indeed, medicine today may be considered the victim of its own success. The changing pattern of disease in the general population from acute to chronic with all the pressure this change exerts on National Health Service resources is, at
6 de-Vries LS, Regev R, Pennock JM, Wigglesworth JS, Dubowitz LM. Ultrasound evolution and later outcome of infants with periventricular densities. Early Hum Dev 1988;16:225-33.

7 McMenamin JB, Shackelford GD, Volpe JJ. Outcome of neonatal intraventricular hemorrhage with periventricular echodense lesions. Ann Neurol 1984; 15:285-90.

8 DiPietro MA, Brody BA, Teele RL. Peritrigonal echogenic 'blush' on cranial sonography: pathologic correlates. AJR 1986;146:1067-72.

9 Grant EG, Schellinger D, Richardson JD, Coffey ML, Smirniotopoulous JG. Echogenic periventricular halo: normal sonographic finding or neonatal cerebral hemorrhage. $A \mathcal{F} R$ 1983;140:793-6.

10 Trounce JQ, Fagan D, Levene MI. Intraventricular haemorrhage and periventricular leucomalacia: ultrasound and autopsy correlation. Arch Dis Child 1986;61:1203-7.

11 Fawer C-L, Calame A, Furrer M-T. Neurodevelopmental outcome at 12 months of age related to cerebral ultrasound appearances of high risk premonths of age related to cerebral ultrasound appen

12 Graziani LJ, Pasto M, Stanley C, et al. Neonatal neurosonographic correlates of cerebral palsy in preterm infants. Pediatrics 1986;78:88-95.

13 Nwaesei CG, Allen AC, Vincer MJ, et al. Effect of timing of cerebral ultrasonography on the prediction of later neurodevelopmental outcome in sonography on the prediction of later neurodevelop
high-risk preterm infants. $\mathcal{F}$ Pediatr $1988 ; 112: 970-5$

14 Guzzetta F, Shackelford GD, Volpe S, Perlman JM, Volpe JJ. Periventricular intraparenchymal echodensities in the premature newborn: critical determinant of neurologic outcome. Pediatrics 1986;78:995-1006.

15 De-Vries LS, Dubowitz LMS, Dubowitz V, et al. Predictive value of cranial ultrasound in the newborn baby: a reappraisal. Lancet 1985;ii:137-40.

least in part, due to an increase in prevalence of many diseases, the consequences of effective medical intervention.

At a more specific level, the relationship between incidence and prevalence must be invoked in the debate on the levels of impairment and disability associated with improved survival of low birthweight infants-that is, in the outcome audit of obstetric and neonatal intensive care.

First, it is not valid to refer to incidence for any disease in which the aetiological agent is thought to act prenatally unless it is possible to determine how many affected conceptuses were aborted or lost as stillbirths. At the best, all that can be determined for these conditions is the prevalence at birth. The congenital anomalies and probably the vast majority of cases of cerebral palsy fall into this category. Currently the debate centres around reports that there is an increasing prevalence of cerebral palsy among very low birthweight infants and how the increase is related to either obstetric and/or neonatal management. If the prevalence is increasing it can be due to an increase in either incidence or duration, or both.

To take duration first, the assumption has to be that the infant is brain damaged prepartum and changes in obstetric/ neonatal management merely improve survival of affected infants-that is, prevalence is increased because of a greater duration of the condition. This being so, further advances in care can be expected to result in a higher prevalence of cerebral palsy.

The alternative explanation is that prevalence is increasing because of an increased incidence-that is, new cases are being produced as a result of brain damage inflicted in the peripartum period. Implicit in this explanation is that peripartum management must, in some way, have been suboptimal with all the medicolegal spectres this raises.

Recently there has been discussion about whether demonstrable intracranial lesions, for example, periventricular leucomalacia or intraventricular haemorrhage associated with anoxic or other insults cause the cerebral palsy, or whether these insults are more prone to occur in the infant whose brain has already been compromised. In this context, Koch's postulates need to be applied to cerebral palsy.

Department of Public Health,

P O D PHAROAH

University of Liverpool,

PO Box 147

Liverpool L69 3BX 